\title{
Understanding peat carbon sequestration on Earth
}

\author{
Zicheng Yu', D. Charman², D. Beilman ${ }^{3}$ and J. Nichols ${ }^{4}$ \\ 1st C-PEAT workshop, New York, USA, 11-13 October 2015
}

Peats represent a large, and often active, carbon (C) pool in the land-atmosphere system. At present, these $\mathrm{C}$-rich deposits contain about $600 \mathrm{Pg}$, an amount similar to the total $C$ stocks in all living biomass or in the atmosphere. The large size of the peat $C$ pool and its concentration in a number of regions sensitive to climate change and human activities have promoted a heightened interest and increased research in peat $\mathrm{C}$ dynamics. Over the last decade, we have learned much about their distributions, histories and controls as a result of sitelevel, data synthesis, and modeling studies. However, large uncertainties remain in C sequestration rates and stocks, in our understanding of the underlying processes, and in our ability to project their future trajectories. PAGES' C-PEAT (Carbon in Peat on EArth through Time) working group was established in 2014 to coordinate peat $C$ researchers to make important progress on data synthesis and process-level understanding from an integrated, global and Earth history perspective.

The C-PEAT launch workshop focused on three overarching themes: (1) the controls on peat formation (why is there peat?); (2) the estimates of peat $C$ stocks and accumulation rates in Earth history; and (3) the future trajectories of peat $C$ stocks. A total of 52 participants including many early-career researchers from 10 countries attended the workshop. Short presentations were followed by plenary and breakout group dis cussions. Details on the workshop program and presentations can be found on the workshop webpage (www.pastglobalchanges.org/ calendar/all-events/127-pages/1502-c-peatlaunch-wshop).

This workshop built on several recent synthesis efforts. The largest peatland region in the circum-Arctic, representing about $90 \%$ of global peat $\mathrm{C}$ stocks, was the focus of a workshop in October 2013 (Yu and Loisel 2014). A mini-workshop was held in October 2014 on circum-Antarctic peats, including Patagonian peatlands and Antarctic moss peat banks. To complement these efforts, this C-PEAT workshop focused on tropical peatlands, buried peats, deep-time peats and coals, and peat vulnerability (Fig. 1).

The breakout group discussions focused on these topics and the three overarching themes. In particular, a group of tropical peatland researchers discussed the best ways to generate an updated synthesis from tropical peatlands in different regions. Compiling information regarding buried peats under mineral soils or on continental shelves will help identify and quantify "missing" peat $C$ as simulated in some models. A first ever involvement of several deeptime wetland and coal researchers in a peat workshop generated exciting discussions about approaches to estimate equivalent $C$ accumulation rates from deep-time peat and coal deposits. Regarding peat $C$ vulnerability, ideas emerged regarding rapid modern and future loss of tropical peats due to human activities, and potential for new peats in frontier regions, such as the Arctic and Antarctica, in response to a warmer and possibly wetter climate. On the question about why there is peat, we considered that reduced decay of initial organic matter is critical - often achieved by waterlogging (especially in tropical peatlands), by the presence of permafrost (including aerobic peatbanks in the High Arctic and Antarctica), or by cold environmental conditions. Also, recent progress in global peatland modeling (e.g. Stocker et al. 2014) and peat data synthesis (Loisel et al. 2014) will likely lead to more productive data-model comparisons.

During the next couple of years of C-PEAT Phase 1, these topical groups will coordinate and organize focused meetings and workshops to generate synthesis products. We plan a workshop focused on tropical peats in early 2017 and a synthesis workshop, for all C-PEAT members, in late 2017.

\section{ACKNOWLEDGEMENTS}

We thank PAGES, INQUA, NSF (Antarctic Earth

Sciences grant 1246190) and Lehigh's Department of Earth and Environmental Sciences for financial support, and LDEO for hosting the workshop.

\section{AFFILIATIONS}

'Department of Earth and Environmental Sciences, Lehigh University, Bethlehem, USA

${ }^{2}$ Department of Geography, University of Exeter, UK ${ }^{3}$ Department of Geography, University of Hawaii at Manoa, Honolulu, USA

${ }^{4}$ Lamont-Doherty Earth Observatory at Columbia University, Palisades, USA

CONTACT

Zicheng Yu: ziy2@lehigh.edu

REFERENCES

Loisel J et al. (2014) Holocene 24: 1028-1042

Stocker B et al. (2014) Geosci Model Dev 7: 3089-3110 Yu ZC, Loisel J (2014) PAGES Mag 22: 41

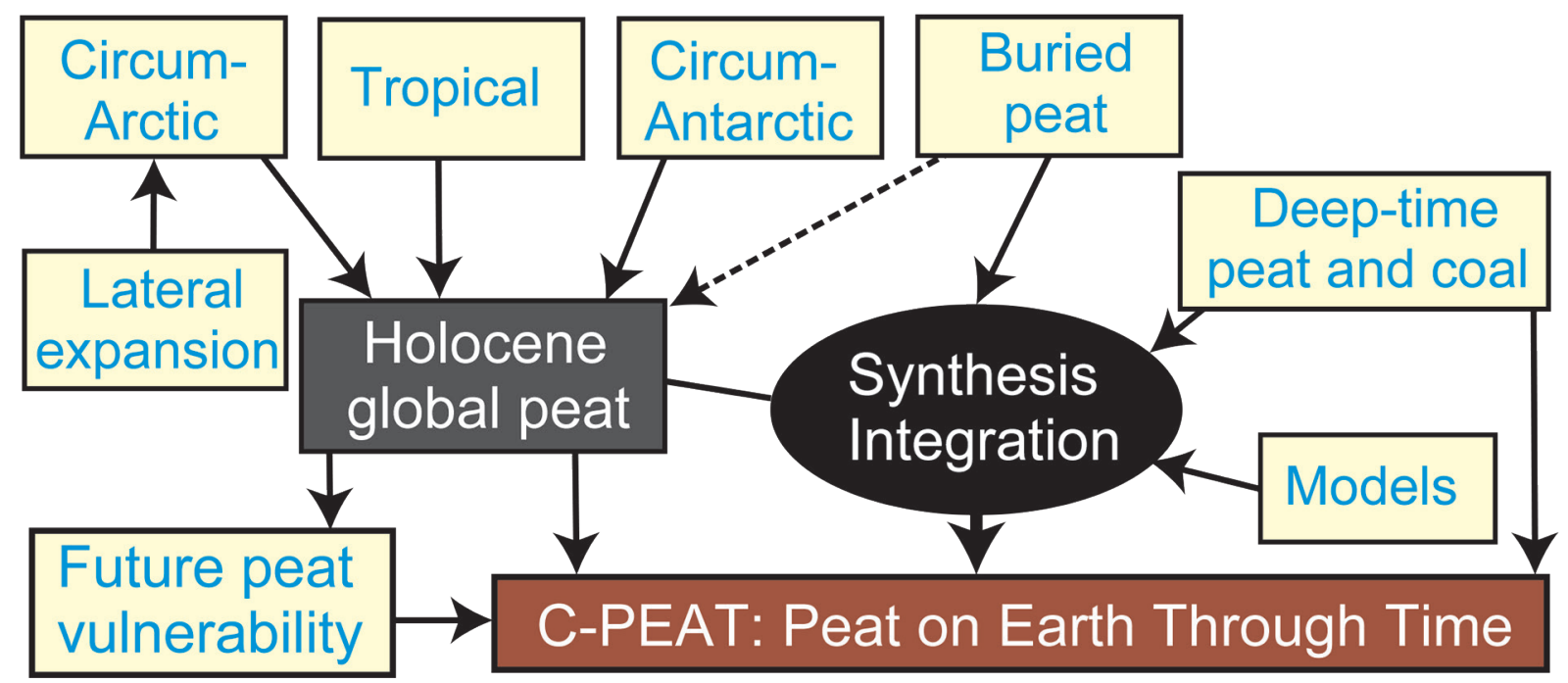

Figure 1: C-PEAT topical groups (yellow boxes) aim to facilitate the synthesis of data and knowledge of global Holocene peat $C$ stocks and accumulation rates from northern tropical and southern peatlands and their future trajectories, and to improve our understanding of peat accumulation processes and roles in Earth climate system over time through integrating Holocene and deep-time peat data and ideas. 